\title{
Harnessing the Digital Exhaust: Incorporating Wellness into the Pharma Model
}

\author{
Justin M. Wright ${ }^{a} \quad$ Graham Barry Jones ${ }^{b}$ \\ ${ }^{a}$ Technical Research and Development, Novartis Pharmaceuticals, East Hanover, NJ, USA; \\ ${ }^{b}$ Clinical and Translational Science Institute, Tufts Medical Center, Boston, MA, USA
}

\author{
Keywords \\ Digital biomarkers $\cdot$ Wellness $\cdot$ Diagnostics $\cdot$ Closed loop $\cdot$ Patient engagement
}

\begin{abstract}
The increasing availability of devices capable of tracking biomarkers presents major opportunities in contemporary healthcare. Herein we advocate a new role for the pharmaceutical industry to capitalize on these opportunities and, in doing so, incorporate wellness and patient engagement programs into their standard business models. Medical-grade decision-making using diagnostic, prognostic, and monitoring biomarkers will require coordinated approaches between the pharmaceutical and technology industries and the careful design of longitudinal clinical studies to validate their efficacy. These studies will also require data capture, archiving, curating, and sharing on a previously unprecedented scale, and raise additional concerns with regard to data security and ownership. Concurrently, systems-based approaches to the capture and interpretation of a new class of digital biomarkers are emerging, and they hold promise for heightened levels of patient engagement and remote sensing. Collectively, if these new opportunities are approached within the context of the patient-provider ecosystem, major repositioning of the pharmaceutical industry may be possible in the near future.
\end{abstract}

(c) 2018 The Author(s)

Published by S. Karger AG, Basel

\section{Introduction}

The pharmaceutical sector remains one of the largest components of the US and global economies, with sales exceeding USD 450 billion domestically and USD 900 billion worldwide. Historically the industry has relied on the "blockbuster" model for drug entry, where drugs with USD 1 billion or more of annual sales allow investments to be made in early-stage 
Wright and Jones: Harnessing the Digital Exhaust

projects and smaller markets. Estimates of the cost of launching a new drug range upwards of USD 2 billion, a model which has been described as unsustainable [1]. The industry is also undergoing a transformation as traditional small molecule drugs are supplanted by nextgeneration protein-based biotechnology products manufactured from cell cultures [2]. This is the fastest-growing component of the pharmaceutical sector, and has led to a number of mergers and acquisitions between pharmaceutical and biotechnology corporations. Additional pressures on the sector have emerged with the introduction of regulatory approval pathways for biosimilar versions of these drugs (a counterpart to the Hatch-Waxman-inspired process for small molecule generics) [3] and it is estimated that some USD 50 billion of innovator products will be subject to competition by 2020 [4].

Against this backdrop the pharmaceutical business model is evolving rapidly, with many organizations seeking niche markets within which to develop new products. One example is in the area of orphan/rare diseases, where accelerated regulatory pathways are offered in markets with $<200,000$ patients [5]. A natural consequence of this has been to use genomic and proteomic profiling methods to identify subcategories of diseases and develop selective therapeutics therein - an example being triple-negative breast cancer [6]. These activities have spurred a rapid growth in the emergence of "companion" diagnostics, where a drug $\left(\mathrm{R}_{\mathrm{X}}\right)$ is prescribed based on positive indications in patients with a defined diagnostic $\left(D_{X}\right)$ [7].

Comprehensive regulatory guidance has recently been developed by the FDA for these and related forms of biomarkers which can now be classified into one of seven categories: (a) susceptibility/risk biomarkers, (b) diagnostic biomarkers, (c) monitoring biomarkers, (d) prognostic biomarkers, (e) predictive biomarkers, (f) pharmacodynamic/response biomarkers, and (g) safety biomarkers [8]. Collectively, they are responsive to a broader agenda often referred to as the "precision medicine" initiative [9], and in some cases digital versions of these biomarkers have been identified, defined as "consumer-generated physiological and behavioral measures collected through connected digital tools" [10]. Given these classifications, it has become clear that the regulatory agencies view biomarkers contextually, and this will prompt and encourage the pharmaceutical industry to consider additional approaches and products.

\section{The Closed-Loop Approach to Disease Management}

While existing activities are likely to continue to fuel the growth of the pharmaceutical industry, there are other developments proceeding at a rapid pace which could cause the sector to reexamine its business model [11]. In essence, the pharmaceutical industry is responsive to a treatment market driven by diseases afflicting its patients. In contrast, vaccine programs, developed by a smaller subset of pharmaceutical companies, function by disease prevention. Though having a profound impact on global health, unfortunately vaccines are not currently available for a large number of acute and chronic diseases [12]. A third pathway, which has now been demonstrated in closed-loop systems, is disease management. The strategy involves the release of a therapeutic agent on demand, stimulated by response to a biomarker.

Though examples of patient-activated responses are legion - e.g., self-administration of a nonsteroidal anti-inflammatory drug at the first sign of fever or epinephrine administration at the onset of anaphylaxis - the ability to automate the process is noteworthy. The first example of this in the form of a device which has been approved by the FDA is in the diabetes mellitus space [13]. Specifically, the MiniMed 670G, developed by Medtronic, delivers a bolus of insulin from a reservoir in response to a signal from a controller which monitors circulating glucose levels - a primary biomarker for type 1 diabetes. 
Wright and Jones: Harnessing the Digital Exhaust

The ability to achieve homeostasis without patient interaction (or even their knowledge) is significant, and application of the strategy in other therapeutic areas is inviting. In the case of the MiniMed 670G, the biomarker sensor is an embedded device. While effective, the needle of the device is certainly invasive, and its embedded sensor is subject to interactions with the dermal and subcutaneous layers, collectively inducing what is referred to as a "foreign body reaction," which includes an inflammatory response [14]. Accordingly, a number of strategies are being investigated for noninvasive glucose monitoring, including saliva assays [15], colorimetric assays [16], and tear sensors, one example being a smart contact lens, complete with integrated circuitry to transmit data wirelessly to a controller [17]. It will be interesting to watch the market mature in this and other sectors, with current estimates suggesting the US diabetes market alone is USD 20 billion or more.

This notwithstanding, based on rapid advances in digital technologies, a large number of consumer devices (both regulated and unregulated) have recently been developed which are capable of monitoring select biomarkers. Harnessing these data to track patients' health indicators longitudinally offers myriad opportunities, both in disease diagnosis and management, but perhaps more powerfully by monitoring wellness and detecting prodromal stages of disease. Herein, we submit that if deployed appropriately in an integrated manner, they offer the potential for pharmaceutical companies to extend their footprint and rebrand themselves as wellness organizations to supplement or even supplant their traditionally perceived role. The range of sensors and biomarkers they are capable of tracking is ever increasing, and, coupled with potential changes in healthcare reimbursement models, represents an important juncture and opportunity for the industry to consider [18].

\section{The Digital Signature and Exhaust}

Augmenting progress in devices that measure traditional (liquid) biomarkers, the emergence of wrist-based and handheld devices capable of recording and tracking biomarkers digitally has been dramatic. Smartphones routinely possess basic step counters to allow owners to track physical activity, and a number of smart watches contain sophisticated sensors including photoplethysmograms and other circuitry to allow estimates of blood pressure, oxygen saturation, and body temperature, and customized accelerometers that can examine both mobility and gait [19].

Recent reports suggest that over 300,000 health-related apps have been developed, together with over 340 patient-worn devices [20]. Translating these opportunities (which will involve recording of patients' so-called digital signatures) into FDA-approved devices which can provide clinical-grade data will be a major objective over the coming years, and initial guidance documents have started to emerge [21]. How such systems are deployed and cross-communicate with other devices represents a systems engineering challenge that may on first examination be perplexing for the medical software and device industries, which typically are grounded in very different business cultures.

It is instructive in this regard to examine comparisons with industries which have been transformed by use of sensor and systems technologies, and both the aircraft and automotive industries fit into this category. A typical automobile is equipped with over 100 sensors, which monitor myriad functions connected with performance, safety, emissions, and speed. These sensors are deployed in systems-based categories, and are connected via an engine management system (Fig. 1). Subsets of curated data from these sensors are presented visually to the driver in the form of warnings. In some vehicles, the display dashboard is capable of highlighting more than 60 sensors, and provision also exists for transmission of certain data to the service department of the manufacturer/dealer (Fig. 2). Detailed data can 


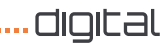

DI๑markers

Fig. 1. Automotive systems map.

\begin{tabular}{l|l}
\hline Digit Biomark 2018;2:31-46 \\
\hline DOI: 10.1159/000488132 & $\begin{array}{l}\text { @ } 2018 \text { The Author(s). Published by S. Karger AG, Basel } \\
\text { www.karger.com/dib }\end{array}$ \\
\hline
\end{tabular}

Wright and Jones: Harnessing the Digital Exhaust

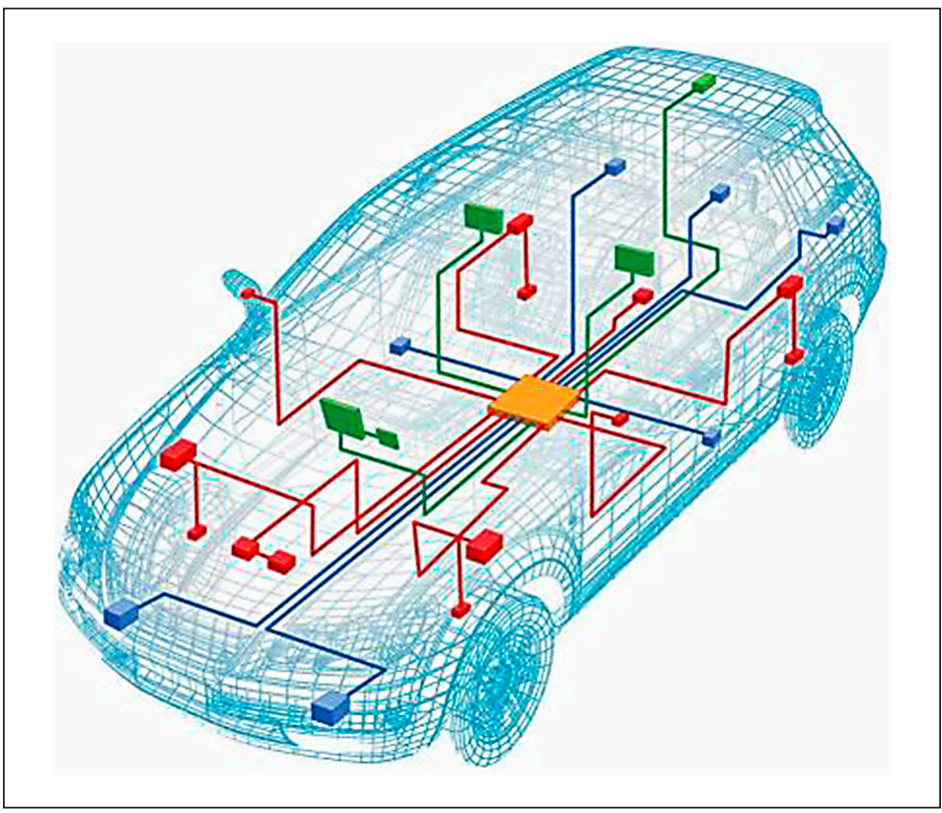

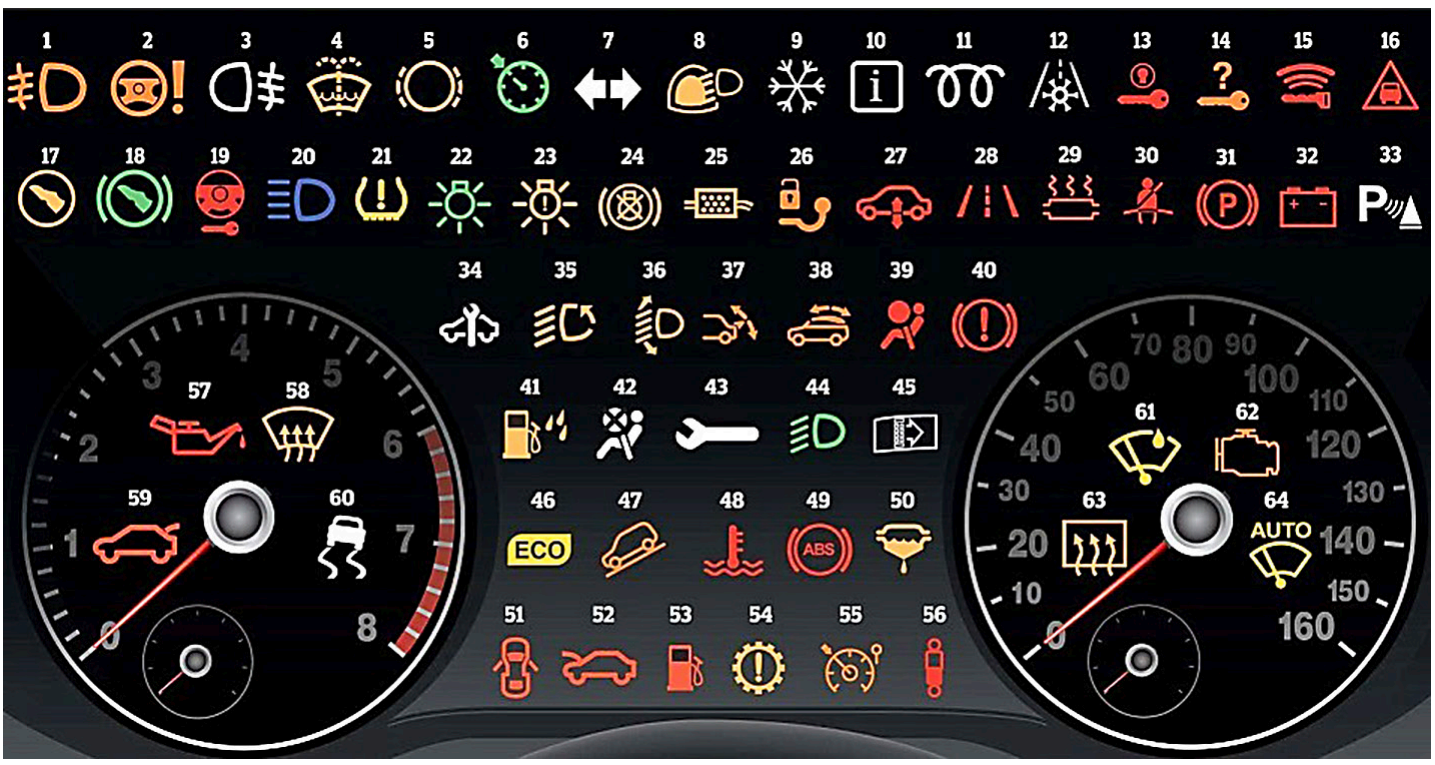

Fig. 2. Visual sensor warning dashboard.

be downloaded in digital format through the vehicles OBDII (onboard diagnostics port), in what is tantamount to a digital health signature of the vehicle [22].

Possible extensions of such approaches to humans and human disease are inviting to make. Medicine has been typically taught and practiced on the basis of the major systems of the body (Fig. 3). The counterpart to the vehicle engine management system would be the brain, and the automotive service department a physician or health provider.

The opportunity to derive meaningful health-related biomarkers from individual systems is considerable and provides impetus for the design and development of new sensors which capitalize on these information-rich and near-limitless data sources (Table 1). If captured 


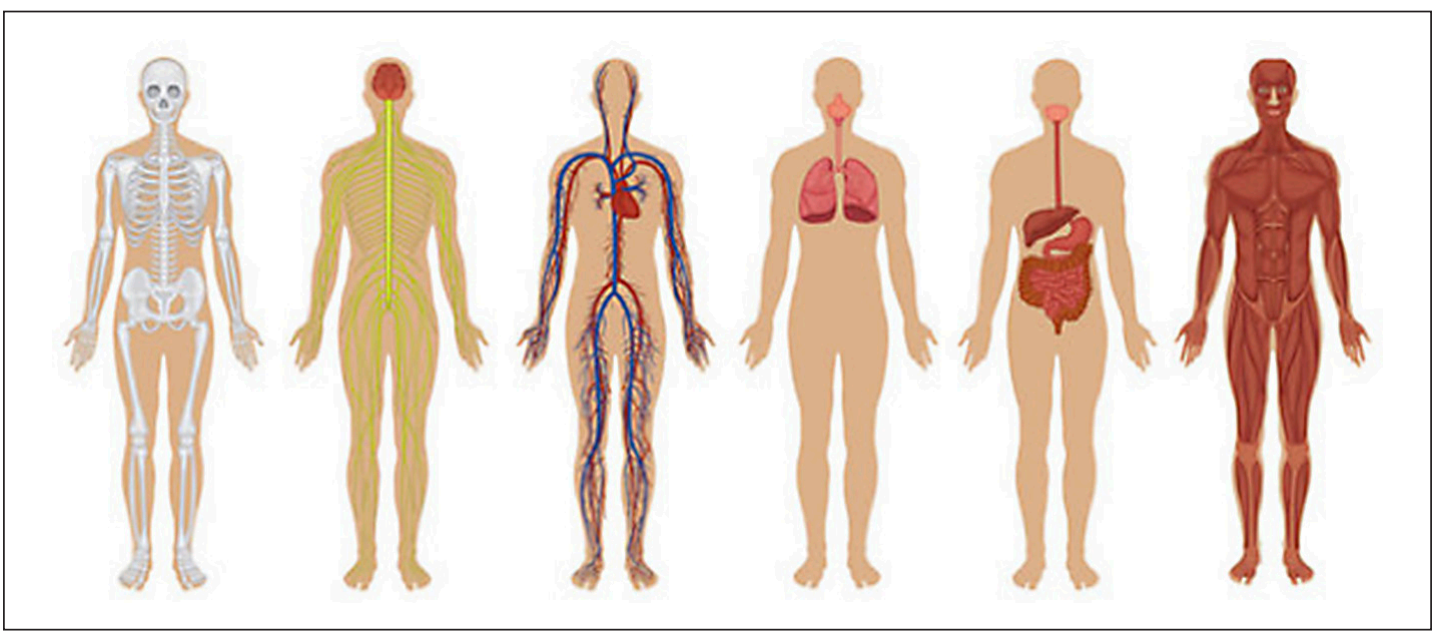

Fig. 3. Human physiological systems.

Table 1. Opportunities for human biomarker sensing

\author{
$>20$ million nerve endings \\ 206 bones, 78 organs, 650 skeletal muscles \\ $>50,000$ discrete proteins \\ Circulatory system stretches 60,000 miles \\ $5 \mathrm{~L}$ blood and $7.5 \mathrm{~L}$ breath pumped/min \\ $\sim 10,000$ unique molecules in diet \\ $\sim 0.7 \mathrm{~kg}$ feces, $2 \mathrm{~L}$ urine, $6 \mathrm{~L}$ sweat, $2 \mathrm{~mL}$ tears, $2 \mathrm{~L}$ saliva/day
}

digitally and longitudinally, such outputs would constitute the "digital exhaust" of a person, the "digital emissions" providing information on the degree of wellness, a composite and wide-ranging equivalent of annual vehicle inspection and emission tests.

Similar correlations exist with regard to aircraft systems, where data are typically recorded and transmitted in real time during the progress of a flight, allowing potential problems to be identified early and maintenance schedules adjusted to prevent the problem from becoming a safety concern. The live streaming of health indicators to a monitoring center will likely become a reality within this century, provided reliable sensors can be developed in vital areas. The aircraft industry, by its very nature, has also pioneered another development with potential to inform human health management: flight data recorders. Commonly known as "black boxes," these devices record complex flight data streams through a flight data recorder and cockpit conversations through a cockpit voice recorder. Captured in real time in a continuous loop, they are designed to provide critical information following a catastrophic event. The closest human analogy would be a postmortem, where a coroner follows specific procedures to determine the cause of death [23]. These are typically conducted from a forensic standpoint as opposed to providing medical-grade information that can be used for subsequent research (an exception being the postmortem diagnosis of Alzheimer disease and chronic traumatic encephalopathy on examination of brain tissue) [24]. One of the principal uses of the aircraft flight data recorder is to use the knowledge gained to correct potential problems on other aircraft, in many cases resulting in the reengineering of entire fleets of specific models (Fig. 4).

The human analogy could in principle involve phenotype-level alerts being issued to the medical community based on combinations of a deceased patient's genetics, lifestyle factors, and triggering events. For example, longitudinal data from subjects prescribed certain medi- 
Fig. 4. Forensic data capture in adverse event management.

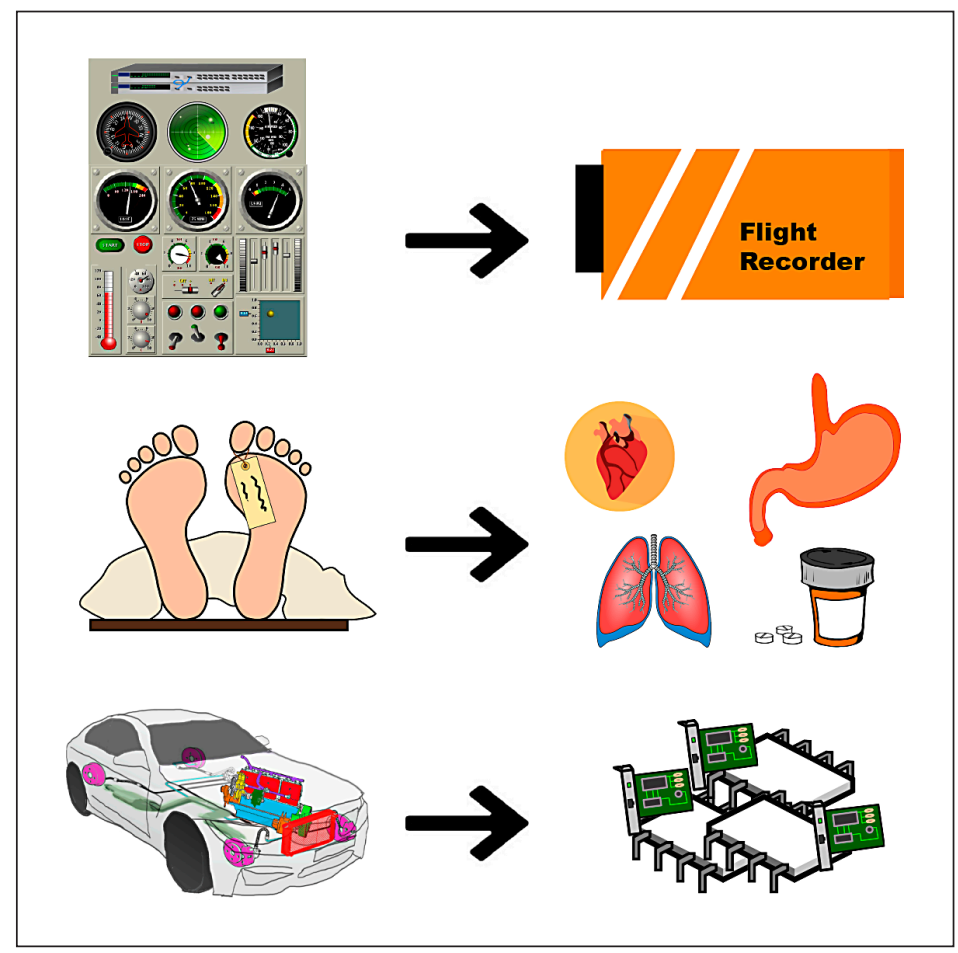

cations over an extended period may highlight potential contraindications and also contributing factors related to specific diets or sleep patterns [25]. To achieve this level of insight would require comprehensive rethinking of the requirements for postmortem examinations, possibly needing to include broad omic-level liquid biopsy, a microbiome (16S rRNA) screen [26], multimodal systems imaging, and uploading of sensor data at the time of death. This would be referenced against the digital exhaust of the subject over a specific time period in order to help identify risk factors. Current autopsy data record organ masses as well as toxicology and hematology panels and highlight any obvious abnormalities [27]. Thus considerable reengineering would be required in addition to the obviously complex legal, ethical, and financial considerations. In the automotive sector, crash sensors which trigger the deployment of passenger safety devices (airbags and air pillows) record information which can be retrieved for diagnostics, e.g., ambient temperature, a vehicle's location, and the speed at the time of impact (Fig. 4).

The similarity of automotive systems management and consumer health tracking may be closer than we anticipate. A new generation of digitally savvy consumers is already using smartphones and computers to diagnose problems with their vehicles. By connecting to the OBDII port of the vehicle, apps are available that provide systems-level information on problems and errors, and that even reset instrument panel warning lights. The same information can also be transmitted wirelessly from the vehicle to a service center.

This touches on a key consideration regarding the illness/wellness conundrum in healthcare. The consumer seeks such vehicle data in a reactive manner, to diagnose a fault. The car dealer may use the same information to recommend the provision of services for the vehicle, in a direct marketing approach. This has overtures of the direct-to-consumer marketing of pharmaceuticals, which has now become ubiquitous. A third consideration would be from an automobile service center assigned a leased/rented vehicle, where maintenance forms part of the contract's terms. It is in the owner's interest to take proactive 


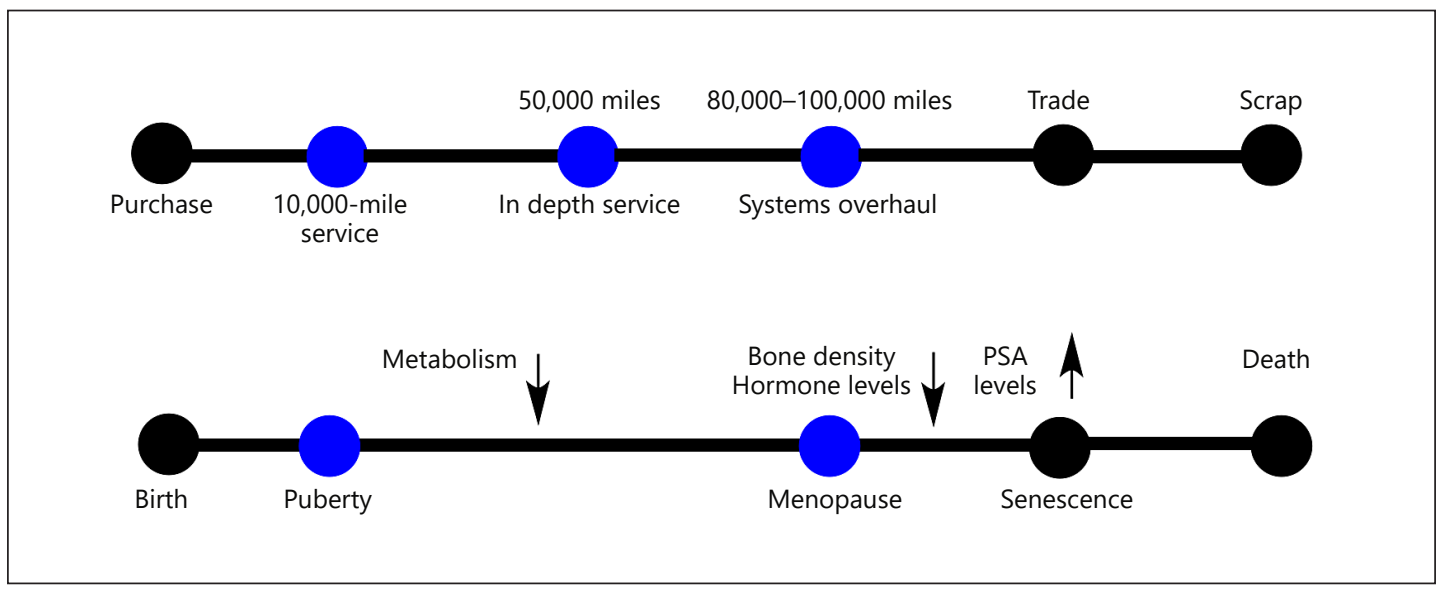

Fig. 5. Defining points in life cycle management of automobiles and health. PSA, prostate-specific antigen.

measures to ensure the vehicle is repaired/serviced at the first sign of a problem, which will (a) reduce subsequent repair costs and (b) help retain the residual market value of the vehicle at the end of the lease/rental term. The correlations with human health decision-making are obvious, the latter example embodying the role of the insurers and end payers. Mechanisms for encouraging patients to take proactive measures with regard to individual healthcare are varied, but there are encouraging signs that the Generation X and Millennials will adopt such measures [28]. The deployment, for example, of a blood pressure sensor the data from which are recorded by a smartphone and uploaded to a provider is both proactive on the part of the subject and the health provider, and such partnerships should ultimately translate into more effective outcomes and lower costs. Harnessing and promoting these types of activity en masse represents a major opportunity for the pharmaceutical industry to become more patient engaged, integrate wellness into its repertoire, and, in the process, redefine its image.

\section{A New Model for Pharma?}

Given the inherent commercial risks associated with bringing new drugs to market, it makes ultimate sense for the pharmaceutical industry to consider diversification strategies. Furthermore, the general association of the industry with illness/disease and the widespread belief that drug costs are artificially high have resulted in a degree of skepticism and negativity surrounding the sector, particularly among the Generation X and Millennials. These groups, however, would seem ideally positioned to embrace a revamped pharmaceutical industry that focused on wellness and health, responsive to their individual needs through new digital medicine platforms.

This requires a rethinking of lifestyle management akin to life cycle management in the case of a vehicle. By way of illustration, a purchaser of a vehicle will usually enjoy free service through at least the first 10,000 miles of its life. Some manufacturers offer this service through to 50,000 miles, at which time basic warranties often expire. The owner typically has the option to purchase an additional warranty/insurance through to 80,000 miles, following which the vehicle will have depreciated significantly. Depending on the costs of annual maintenance and repair, which would be expected to increase dramatically as the vehicle passes the 100,000-mile mark, the owner will often take the decision to trade the vehicle in against a newer model (Fig. 5). In terms of human health, the categories that apply to development 


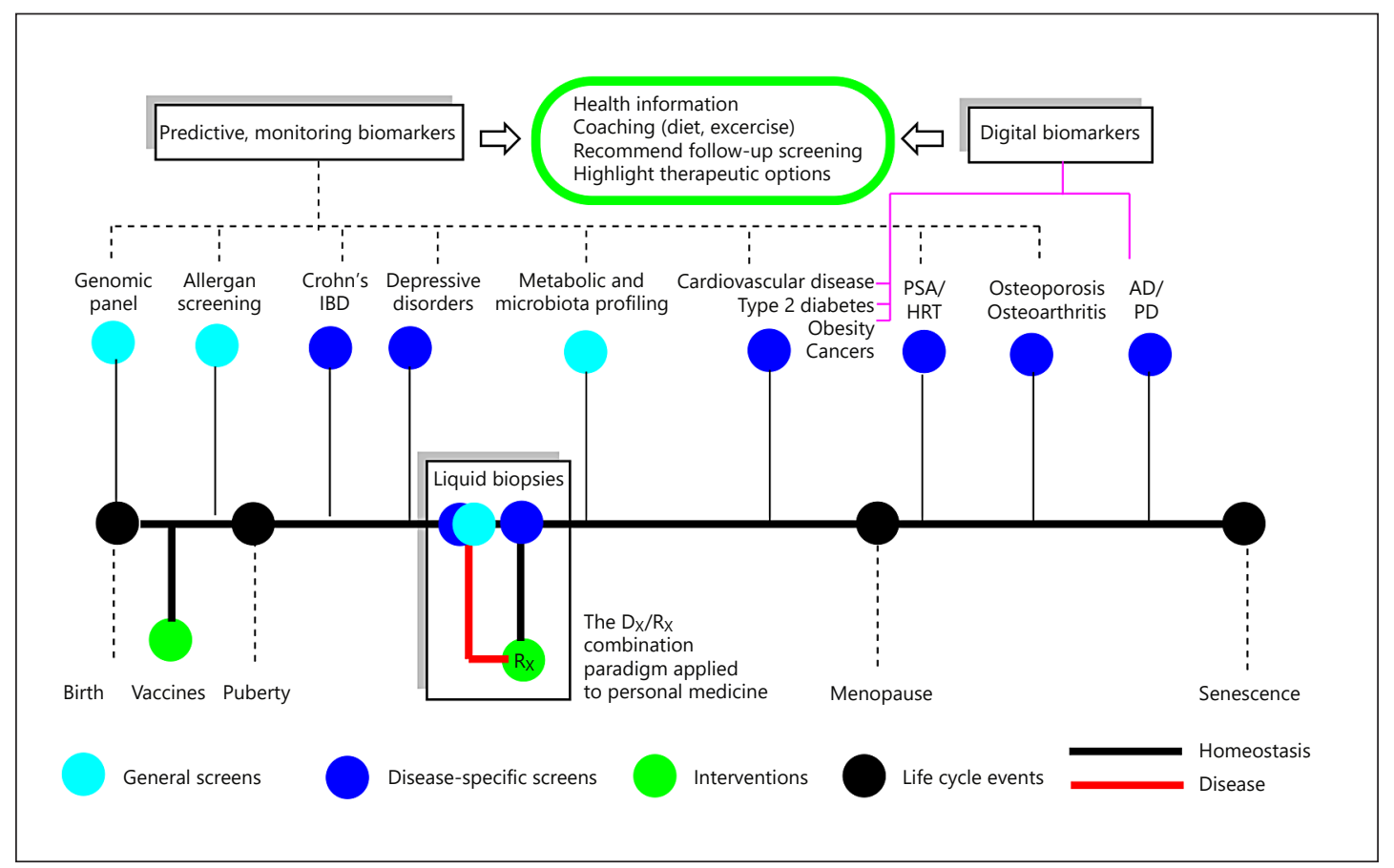

Fig. 6. Recasting pharma as wellness and health maintenance organizations. IBD, inflammatory bowel disease; PSA, prostate-specific antigen; HRT, hormone replacement therapy; AD, Alzheimer disease; PD, Parkinson disease; $R_{X}$, drug; $D_{X}$, diagnostic.

of pharmaceutical drugs are pediatric, adult, and geriatric. In a similar age-related analysis, the elderly population necessarily consumes higher quantities of prescription drugs than do adults and children, and the vehicle warranty analogy correlates to health premium costs, which typically advance significantly with age (supplementing those of Medicare and Medicaid in the USA) [29].

Given the likelihood that many chronic diseases can be detected earlier in life, the pharmaceutical industry is necessarily motivated to investigate diagnostic tools and screening procedures, many of which are currently reimbursed through healthcare programs. The more comprehensive opportunity, however, is to extend the reach across the entire life span. Tracking through life stages, a new pharmaceutical industry model would offer a series of diagnostic tests $\left(D_{X}\right)$ in the form of both general and disease-specific screens. These would involve a combination of conventional liquid biopsy and digital monitoring biomarkers (Fig. 6). Many corporations have a portfolio of vaccines in their repertoire, and this is likely to continue apace, as witnessed in the oncology sector. Genomic panels (at birth) may point to the need for additional vaccines based on genetic risk and other factors. Interventions to detected disease states would involve requisite medications $\left(\mathrm{R}_{\mathrm{X}}\right)$, which in theory could be provided either by the corporation providing the $\mathrm{D}_{\mathrm{X}}$ or a third-party affiliate, similar to the code-sharing and partnership models employed in the airline industry. As life stages are reached, an increasing number of general and disease-specific $D_{X}$ tests would be applied, to allow very early detection of prodromal stages of disease, which would then be managed $\left(R_{X}\right)$ conventionally, presumably with improved outcomes. Developing corporate brand affinity/ loyalty could logically commence at the prenatal stage, and at the neonatal stage the first set of comprehensive biomarkers could be captured. Currently, the traditional heel stick test on a neonate examines for metabolic disorders and a limited battery of genetic disorders. More 
Wright and Jones: Harnessing the Digital Exhaust

comprehensive omic tests and epigenetic analyses could be required, together with a baseline microbiome assessment and CyTOF (cytometry by time of flight) immunophenotyping [30].

Subsequent analyses (akin to service intervals in the automotive sector) could be made through a combination of digital biomarkers (onboard diagnostics) and ex vivo biopsies. Analysis of blood, breath, saliva, and tears can already be conducted on peripherals linked to a smartphone [31], and these composite data could be used to track wellness and provide information on relevant materials as a subject transitions through the juvenile and postpubescent stages (e.g., advice on dietary factors, environmental hazards). In the case of certain cardiovascular and neurological diseases, for example, there is growing evidence that digital biomarkers can provide actionable diagnoses [32]. When sensors alert the health provider on the potential need for therapeutics, the consumer may have the right to use either the diagnostic provider/sponsor or a third-party/independent supplier as dictated by applicable state and federal laws/statutes [33]. The potential for reciprocal agreements between pharmaceutical companies could become a reality in this model, which might in turn stratify which classes of therapeutics individual corporations invested in.

In both early and later stages of life, the tracking technology could be monitored by a family member or care provider who would be responsible for taking interventional action. Examples could range from adjusting dietary components to control a child's blood sugar, to clarifying that an elderly patient had taken their required medication - a situation exacerbated in diseases where memory is impaired (e.g., Alzheimer disease). In addition to alerting patients with options for therapeutic interventions, digitally captured data might prompt patient coaching - e.g., recommending changes in exercise/diet/sleep regimens in response to biomarker changes [34]. Critically, in the case of currently incurable diseases such as Alzheimer disease, a follow-up analysis might be recommended - e.g., a confirmative positron emission tomography scan from which to engage the patient in clinical trials. Managing the patient interface between conventional and digital biopsies will require considerable thought. However, such approaches have the potential to expand and improve patient interfaces with pharmaceutical companies, which is likely to become pivotal in the years ahead.

\section{Early Innovators}

Given the rapidly evolving healthcare landscape, a number of pharmaceutical companies have begun exploring the use of digital tools in earnest. Key drivers identified involve increasing patient engagement, improving health outcome measures, and the desire for deep data analytics [35]. Patient engagement is defined by the Institute for Healthcare Improvement (IHI) as "actions people take for their health and to benefit from care" [36]. Numerous additional strategy documents point to the need for the industry to focus on well-being and the optimal management of illness [35], and this is supported by patient expectations. One study reported that $>60 \%$ of diabetes, $>70 \%$ of asthma, and $>80 \%$ of schizophrenia patients expected the drug company to provide assistance beyond the medication [37].

Accordingly, a number of partnerships between pharmaceutical and health technology companies have recently been formed. For example, Biogen has deployed Fitbit devices to monitor the walking activities of its multiple sclerosis patients [38] and Sanofi are now working with Verily Life Sciences on patient support for diabetics [39]. In terms of drug delivery, GlaxoSmithKline are collaborating with Propeller Health on a digital respiratory health management system for use with inhalers [37]. Pfizer has initiated a collaborative venture with Akili Interactive Labs to develop a digital biomarker assessment tool for Alzheimer patients [40]. Boehringer Ingelheim have even established a dedicated new start-up (BI X) as a platform for digital transformation in data science, software development, 
Wright and Jones: Harnessing the Digital Exhaust

and user experience design [41]. Johnson \& Johnson, through its LifeScan subsidiary, is partnering with WellDoc on use of its BlueStar app for the management of various conditions [42].

With the prospect of reimbursement moving towards outcome-based models, there is natural concern within the pharmaceutical sector regarding patient compliance with medication regimens. Among efforts to address this, Novo Nordisk have partnered with Glooko Inc. to develop apps which allow continuous glucose monitoring among diabetes patients [39]. Novartis established a partnership with Qualcomm using the Proteus "chip-in-a-pill" technology to track medication adherence of patients taking the drug Diovan after organ transplantation [38]. Deployment of this technology reportedly increased compliance from 30 to $80 \%$ within 6 months [38].

Under an entirely different model, rather than purchasing medications, some insurers and employers are signaling interest in the provision of overall solutions. In one case, Livongo Health now provides a digital monitoring service (for type 2 diabetic patients), coupled with a coach who helps people live medication free, in return for subscription to its program [39]. A key overarching theme is the development of digital health technology which is able to increase patient activation and engagement [36]. Patient engagement platforms have been outlined, and they will likely form a major component of the strategies of the pharmaceutical industry in the years ahead.

\section{Challenges and Opportunities}

The convergence of the pharmaceutical and digital technology sectors promises to have a defining impact on healthcare. However, numerous challenges will be experienced, not the least of which will be a clash of cultures between the two sectors. For digital technology companies, it will become a learning experience working with pharmaceutical corporations in what is a highly regulated business where innovation typically proceeds at a more measured pace [43]. Additionally, the typical margins for digital health products are lower than for blockbuster drugs, and realistic expectations will need to be set [39]. The stark contrast in business models can be observed in the products both sectors develop. Technology devices and apps require near-constant upgrades and innovations, typically unconstrained by regulatory burdens, in contrast to drug products, which once approved and introduced to the market are rarely modified in any form, as mandated by the regulatory agencies [43]. There may also be concerns regarding brand affinity among patients. Most early-stage digital technology companies have developed strong ties to their patient and physician networks, and the introduction of a partner from the pharmaceutical sector may temper enthusiasm or even prompt a degree of skepticism. These early innovators often cherish their roles as technology pioneers, holding highly positive perceptions regarding the industry and its contributions to advancing society.

A major, perhaps defining issue is related to the actual data captured through these technologies - both in volume and complexity. It is reasonable to conclude that future leaders in the pharmaceutical sector will be those with access to large quantities of highly granular patient data. Signaling its intent in the field, IBM has recently acquired a number of companies (Truven Health Analytics, Explorys, Merge, and Phytel) which collectively own substantial collections of such data that can be used for analytics [39]. One such application is a joint program between IBM Watson and Pfizer on data analytics for immuno-oncology [39]. The role of artificial intelligence in data interrogation is likely to be an area of future focus, and companies such as Google, Baidu, and Yahoo have announced their investment in this area and machine learning to study patient behavior and response to disease [39].

A natural concern as digital health evolved was the need for adequate data security and storage solutions. However, a number of products have now been developed for compre- 


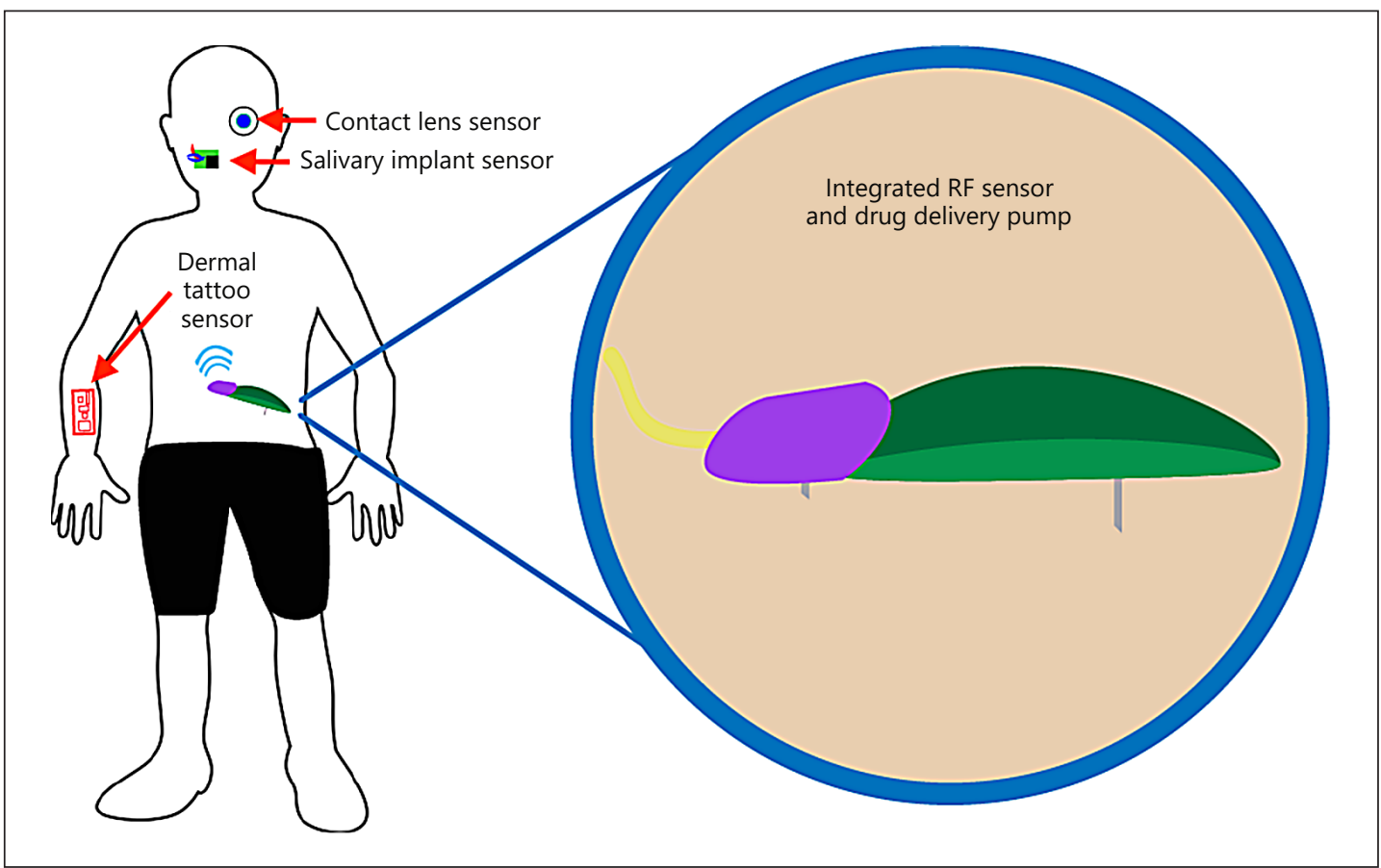

Fig. 7. Sample components of a multisensor, closed-loop drug delivery system. RF, radiofrequency.

hensive patient medical data storage and access, a prominent example being Microsoft's HealthVault [36]. As health-related apps evolve there will also be merit in approaches which reduce the need for enormous data sets. Among leaders in this approach is Cardiogram - e.g., through its DeepHeart product, a semi-supervised neural network that accurately predicts cardiovascular risk but requires 10 times fewer labeled data than conventional techniques [44]. Interesting developments can also be expected with regard to access to patients' omic information by the pharmaceutical industry. For example, through the personalized genomic sequencing services recently outlined by Nebula [45] and Luna [46], patients can grant pharmaceutical companies access to data in return for provision of services, using a blockchaintype financing model.

As these relationships evolve, they will help reposition the pharmaceutical industry in the eyes of the consumer prior to the onset of any disease, consistent with the notion of becoming wellness oriented. Ultimately, financial pressure on the industry and providers will likely drive a number of measures and innovations. For example, on patient prescription medication compliance alone, the US Congressional Budget Office has estimated that a $1 \%$ improvement could translate into nearly USD 2 billion in savings for the Medicare budget [36].

\section{Over the Horizon: The Closed-Loop "Autopharmacy"?}

The impact of digital technologies on medicine seems certain to help evolve managed healthcare, with patient experiences and patient outcomes front and center. Technology can also be expected to alter the methods which we actually employ to detect and treat the symptoms of disease. An ultimate expression of a disease detection-intervention tool would be in the form of an integrated closed-loop disease management system (Fig. 7). In 


\begin{tabular}{l|l}
\hline Digit Biomark 2018;2:31-46 \\
\hline DOI: 10.1159/000488132 & $\begin{array}{l}\text { (c) 2018 The Author(s). Published by S. Karger AG, Basel } \\
\text { www.karger.com/dib }\end{array}$
\end{tabular}

Wright and Jones: Harnessing the Digital Exhaust

Table 2. Applications of closedloop disease management

\begin{tabular}{llll}
\hline Sensor & Biomarker & Presentation & Intervention \\
\hline Serotonin & Chemical & Depression & SSRI \\
Cortisol & Chemical & Stress & Ketoconazole \\
Peanut allergens & Chemical & Anaphylaxis & Epinephrine \\
Snake venom & Chemical & Thrombosis & Antivenom Ig \\
Concussion & Physical & Blood clot & Coumadin \\
Temp/HR/GPS & Digital & Lyme disease & Doxycycline \\
Temp/viral/GPS & Digital & SARS, avian flu & Quarantine \\
\hline
\end{tabular}

this approach, various positioned sensors $\left(D_{\mathrm{X}}\right)$ would track key biomarkers and communicate with a wireless hub. When prompted, the hub would intervene - e.g., by the deployment of a drug $\left(\mathrm{R}_{\mathrm{X}}\right)$ from a closed-loop delivery device, akin to an automated pharmacy on demand. Such possibilities, originally confined to the realm of science fiction, have now been reduced to practice, as evidenced by the MiniMed 670G closed-loop glucose detector/insulin injector.

There are myriad additional applications, which are currently only curbed by the limited availability of appropriate miniaturized sensors that might be deployed (Table 2). For example, a patient suffering from depression and with a history of noncompliance with medication regimens might benefit from the release of a selective serotonin reuptake inhibitor when neurotransmitter levels fall below a predetermined threshold. Likewise, a patient suffering from high stress levels might benefit from automated delivery of a medicament when cortisol (or other biomarker) levels peak [47]. Such devices could become highly miniaturized and incorporate patient-inspired form factors - e.g., using transdermal patches for drug release [48]. An even more time-sensitive application could be the detection of food-based allergens, necessitating the immediate release of an antidote to combat anaphylaxis - e.g., of epinephrine on detection of a peanut allergen or the rapid release of antitoxins for at-risk workers. Other biomarkers might be physical and not chemical. For example, a major concern following concussion is the subsequent formation of blood clots. A sensor able to detect such an event (e.g., blunt force impact) could trigger the release of a platelet-activating factor antagonist or anticoagulant. Similar considerations apply to stroke and microstroke victims, and precision monitors could presumably be engineered to pinpoint the onset of ischemic events.

Sensors can also be designed which monitor multiple digital biomarkers. A recent study correlated temperature and heart rate fluctuations with GPS data to indicate patient contraction of Lyme disease [49]. The rapid introduction of an antibiotic from a closed-loop system could presumably improve outcomes. Sometimes the sensors would detect a disease condition where no medication is available but an intervention is needed - e.g., border quarantine in response to the detection of SARS (severe acute respiratory syndrome) or other pandemics. These automated actions may appear visionary, but they could be implemented with sufficient demand and progress in miniaturized sensor design. Using the vehicle analogy, we now take for granted myriad automated actions in response to stimuli. Some we visually perceive (e.g., rain sensors triggering windshield wipers, automatic headlights, and parking warning devices), some we only feel (e.g., traction control devices and antilock brakes), and others we are entirely oblivious to even though they are essential (e.g., a thermostat opening the engine cooling system). Accordingly, it can be expected that our perceptions of managed healthcare and wellness will alter as new developments and systems are introduced. 
Wright and Jones: Harnessing the Digital Exhaust

\section{Conclusions and Outlook}

We have now entered a period where advances in our understanding of disease, coupled with new diagnostic technologies (both conventional and digital), have the potential for a revolutionary impact on patient care. A related set of technologies which focuses on health maintenance and wellness has also emerged, in some cases traversing the illness/wellness boundary. Viewed holistically, using technology to track the wellness-illness continuum over a subject's life span represents a logical approach to managed healthcare, allowing among other things early diagnosis. Given their current and expanding portfolio of conventional therapeutic and diagnostic products, such represents a timely and opportune juncture for the pharmaceutical industry to rebrand itself in the wellness/illness continuum, as patient-centered lifestyle corporations. This will require close collaboration between industry and technology corporations.

In the design of new model care systems, it is instructive to learn from other regulated industries with experience in event sensing/monitoring and user-data interfaces. It is also an opportune moment to evaluate potential changes in standard medical practice, as well as the benefits of patient screening from the neonatal stage through autopsy, if the full benefits of digital medicine are to be realized. Exciting developments in disease management are also on the horizon, including closed-loop systems which function akin to an automated pharmacy. The first example of a designed device capable of adapting itself to its environment was the Homeostat, developed by W. Ross Ashby in 1948 [50]. In the following seven decades we have witnessed tremendous progress in disease management, and Ashby would surely be delighted with the repertoire of options we have at our disposal to achieve patient homeostasis [51].

The strategy of playing late-stage disease "whack-a-mole" using combination chemotherapeutics is being supplanted by methods which offer digital and molecular-level precision, and promise to transform medicine in ways previously unimaginable to us [52]. Warning signs regarding the need for the pharmaceutical industry to entertain new business models are legion [53]. Proposed mergers of point-of-delivery pharmacies with managed healthcare organizations will serve to increase pressure on the marketplace [54], as will potential changes in reimbursement models. That said, there is growing acceptance on the part of patients' willingness to share medical data records $[45,46,55]$, coupled with compelling evidence that early diagnosis - in the prodromal stages of disease - can translate into improved outcomes and intervention strategies [56,57]. Together, this sets the stage for the dynamic growth of digitally informed medicine as the backbone of contemporary healthcare. It is a field that the pharmaceutical industry can help define and that may lead to new business models within the industry, as witnessed by the code-sharing and partnership alliances seen in the airline sector. The need for this engagement is becoming acute, driven by both ethical and financial considerations.

While the focus on wellness is a central tenet for extending life expectancy, since longevity has steadily increased worldwide, considerations of later-stage quality of life have now become of heightened importance. This is particularly relevant as debilitating neurological disorders increasingly afflict senior populations, where an early diagnosis offers promise for interventions. There exists hope and growing optimism that digital technologies can play a lead role in the battle against these diseases, and in the process show the medical community how wellness screening based on digital medicine can help drive tangible solutions. It will thus be interesting to observe how the pharmaceutical industry responds to these opportunities over the coming decades. 


\begin{tabular}{l|l}
\hline Digit Biomark 2018;2:31-46 \\
\hline DOI: 10.1159/000488132 & $\begin{array}{l}\text { @ } 2018 \text { The Author(s). Published by S. Karger AG, Basel } \\
\text { www.karger.com/dib }\end{array}$
\end{tabular}

Wright and Jones: Harnessing the Digital Exhaust

\section{Acknowledgements}

The authors thank William A. Jones for creating the figures.

\section{Statement of Ethics}

The authors have no ethical conflicts to disclose.

\section{Disclosure Statement}

The authors have no conflicts of interest to declare.

\section{Funding Sources}

G.B.J. acknowledges funding from the NIH National Center for Advancing Translational Sciences through grant UL1 TR001064.

\section{Author Contributions}

J.M.W. and G.B.J. developed and wrote the entire article and assembled it for submission.

\section{References}

1 Mullard A: New drugs cost US $\$ 2.6$ billion to develop. Nat Rev Drug Discov 2014;13:877.

2 Wager K, Jones GB: The forward path for biopharmaceuticals and biosimilars: emerging options in the selection of host cell systems. Curr Biotechnol 2012;1:297-317.

3 Berkowitz SA, Engen JR, Mazzeo JR, Jones GB: Analytical tools for characterizing biopharmaceuticals and the implications for biosimilars. Nat Rev Drug Discov 2012;11:527-540.

4 Brinckerhoff CC, Schorr K: Patent watch: have the biosimilar floodgates been opened in the United States? Nat Rev Drug Discov 2015;14:303-304.

5 Haffner ME: Adopting orphan drugs - two dozen years of treating rare diseases. N Engl J Med 2006;354:445447.

6 Guo J, Gong G, Zhang B: Screening and identification of potential biomarkers in triple-negative breast cancer by integrated analysis. Oncol Rep 2017;38:2219-2228.

7 Jørgensen JT, Hersom M: Companion diagnostics - a tool to improve pharmacotherapy. Ann Transl Med 2016; $4: 482$.

8 FDA-NIH Biomarker Working Group: BEST (Biomarkers, EndpointS, and other Tools) Resource. Silver Spring, Food and Drug Administration; Bethesda, National Institutes of Health, 2016. https://www.ncbi.nlm.nih.gov/ books/NBK326791/ (last accessed February 23, 2018).

9 Collins FS, Varmus H: A new initiative on precision medicine. N Engl J Med 2015;372:793-795.

10 Wang T, Azad T, Rajan R: The emerging influence of digital biomarkers on healthcare. 2016. https://rockhealth.com/reports/ (last accessed February 23, 2018).

11 Franz C: Innovation for health: success factors for the research-based pharmaceutical industry; in Franz C, Bieger T, Herrmann A (eds): Evolving Business Models: How CEOs Transform Traditional Companies. Management for Professionals. Springer, 2017, pp 93-112.

12 Moyle PM: Progress in vaccine development. Curr Protoc Microbiol 2015;36:18.1.1-18.1.26.

13 Bergenstal RM, Garg S, Weinzimer SA, Buckingham BA, Bode BW, Tamborlane WV, et al: Safety of a hybrid closed-loop insulin delivery system in patients with type 1 diabetes. JAMA 2016;316:1407-1408.

14 Klopfleisch R, Jung F: The pathology of the foreign body reaction against biomaterials. J Biomed Mater Res Part A 2017;105:927-940.

15 Zhang W, Du Y, Wang ML: Noninvasive glucose monitoring using saliva nano-biosensor. Sensing Biosensing Res 2015;4:23-29. 


\begin{tabular}{|c|c|}
\hline \multicolumn{2}{|l|}{ Digit Biomark 2018;2:31-46 } \\
\hline DOI: 10.1159/000488132 & $\begin{array}{l}\text { (c) } 2018 \text { The Author(s). Published by S. Karger AG, Basel } \\
\text { www.karger.com/dib }\end{array}$ \\
\hline
\end{tabular}

Wright and Jones: Harnessing the Digital Exhaust

16 Srinivasan V, Pamula VK, Fair RB: An integrated digital microfluidic lab-on-a-chip for clinical diagnostics on human physiological fluids. Lab Chip 2004;4:310-315.

17 Verily: Smart lens program: what is the smart lens program. 2018. https://verily.com/projects/sensors/ smart-lens-program/ (last accessed February 23, 2018).

18 Rodarte C: Pharmaceutical perspective: how digital biomarkers and contextual data will enable therapeutic environments. Digit Biomark 2017;1:73-81.

19 Maron JL, Jones GB: How sensors, devices and biomarkers can transform precision medicine: perspectives from a clinical and translational science institute. Clin Ther 2018;40:345-348.

20 Aitken M, Clancy B, Nass D: The growing value of digital health: evidence and impact on human health and the healthcare system. IQVIA Institute Report, November 7, 2017. https://www.iqvia.com/institute/reports/thegrowing-value-of-digital-health.

21 FDA: Medical Devices: Digital Health Software Precertification (Pre-Cert) Program. https://www.fda.gov/ MedicalDevices/DigitalHealth/UCM567265 (last accessed February 23, 2018).

22 Pan Y-J, Yu T-C, Cheng R-S: Using OBD-II data to explore driving behavior model. 2017 International Conference on Applied System Innovation (ICASI), 10.1109/ICASI.2017.7988297.

23 Foroudi F, Cheung K, Duflou J: A comparison of the needle biopsy post mortem with the conventional autopsy. Pathology 1995;27:79-82.

24 Landau SM, Thomas BA, Thurfjell L, Schmidt M, Margolin R, Mintun M, etal: Amyloid PET imaging in Alzheimer's disease: a comparison of three radiotracers. Eur J Nucl Med Mol Imaging 2014;41:1398-1407.

25 Launiainen T, Ojanperä I: Drug concentrations in post-mortem femoral blood compared with therapeutic concentrations in plasma. Drug Test Anal 2014;6:308-316.

26 Huse SM, Ye Y, Zhou Y, Fodor AA: A core human microbiome as viewed through $16 \mathrm{~S}$ rRNA sequence clusters. PLoS One 2012; 7:e34242.

27 Madea B, Rothschild M: The post mortem external examination: determination of the cause and manner of death. Dtsch Arztebl Int 2010;107:575-586; quiz 587-588.

28 Torous J, Rodriguez J, Powell A: The new digital divide for digital biomarkers. Digit Biomark 2017;1:87-91.

29 Alemayehu B, Warner KE: The lifetime distribution of health care costs. Health Serv Res 2004;39:627-642.

30 Bjornson ZB, Nolan GP, Fantl WJ: Single-cell mass cytometry for analysis of immune system functional states. Curr Opin Immunol 2013;25:484-494.

31 Kühnemund M, Wei Q, Darai E, Wang Y, Hernández-Neuta I, Yang Z, et al: Targeted DNA sequencing and in situ mutation analysis using mobile phone microscopy. Nat Comm 2017;8:13913.

32 Vashist SK, Schneider EM, Luong JHT: Commercial smartphone-based devices and smart applications for personalized healthcare monitoring and management. Diagnostics 2014;4:104-128.

33 Nelson G: Automakers agree to "right to repair" deal. Automotive News, January 25, 2014. http://www. autonews.com/article/20140125/RETAIL05/301279936/automakers-agree-to-right-to-repair-deal (last accessed February 23, 2018).

34 Price ND, Magis AT, Earls JC, Glusman G, Levy R, Lausted C, et al: A wellness study of 108 individuals using personal, dense, dynamic data clouds. Nat Biotechnol 2017;35:747-756.

35 Mentesana M, Rotz G, Strang D, Swanick M: 2017 pharmaceuticals and life sciences trends. strategy\&, 2017. https://www.strategyand.pwc.com/trend/2017-life-sciences-trends (last accessed February 23, 2018).

36 Digital Health: A way for pharma companies to be more relevant in healthcare. https://www.strategyand.pwc. com/media/file/Strategyand_Digital-Health.pdf (last accessed February 23, 2018).

37 Saddler B, Arnold M: Beyond the pill - moving past the hype to driving outcomes. http://www.drgdigital.com/ drg-digital-innovation-blog/beyond-the-pill-moving-past-the-hype-to-driving-outcomes (last accessed February 23,2018 ).

38 Bates A: The time is now to move far beyond the pill. https://social.eyeforpharma.com/column/time-nowmove-far-beyond-pill (last accessed February 23, 2018).

39 Neville S: Digital disrupters take big pharma "beyond the pill." Financial Times series Artificial Intelligence in Real Workplaces, April 24, 2017. https://www.ft.com/content/d7a60642-0361-11e7-ace0-1ce02ef0def9 (last accessed February 23, 2018).

40 Akili and Pfizer release positive data from digital biomarker study. Entertainment Close-Up, December 17, 2016. General OneFile. libraries.state.ma.us/login?gwurl=http://go.galegroup.com/ps/i.do?p=ITOF\&sw= $\mathrm{w} \& \mathrm{u}=$ mlin_m_tufts\&v=2.1\&id=GALE\%7CA474118135\&it=r\&asid=cda738b812304a537cc1ee94d07daa82 (last accessed February 23, 2018).

41 BIX. https://www.bix-digital.com (last accessed February 23, 2018).

42 LifeScan. https://www.lifescan.com/about-us (last accessed February 23, 2018).

43 Grootendorst P, Hollis A, Levine DK, Pogge T, Edwards AM: New approaches to rewarding pharmaceutical innovation. CMAJ 2011;183:681-685.

44 Cardiogram. https://cardiogr.am/about/ (last accessed February 23, 2018).

45 Nebula Genomics. https://www.nebulagenomics.io (last accessed February 23, 2018).

46 Luna. https://www.lunadna.com (last accessed February 23, 2018).

47 Cohen H, Benjamin J, Kaplan Z, Kotler M: Administration of high-dose ketoconazole, an inhibitor of steroid synthesis, prevents posttraumatic anxiety in an animal model. Eur Neuropsychopharmacol 2000;10:429-435.

48 Alkilani AZ, McCrudden MT, Donnelly RF: Transdermal drug delivery: innovative pharmaceutical developments based on disruption of the barrier properties of the stratum corneum. Pharmaceutics 2015;7:438-470. 
Wright and Jones: Harnessing the Digital Exhaust

49 Li X, Dunn J, Salins D, Zhou G, Zhou W, Schüssler-Fiorenza Rose SM, et al: Digital health: tracking physiomes and activity using wearable biosensors reveals useful health-related information. PLoS Biol 2017;15:e2001402.

50 Peter A, Cariani PA: The Homeostat as embodiment of adaptive control. Int J Gen Systems 2009;38:139-154.

51 Meister S, Deitersand W, Becker S: Digital health and digital biomarkers - enabling value chains on health data. Curr Dir Biomed Eng 2016;2:577-581.

52 Steinberg D, Horwitz G, Zohar D: Building a business model in digital medicine. Nat Biotechnol 2015;33:910920.

53 Stott K: Pharma's broken business model: an industry on the brink of terminal decline. Endpoints News, November 28, 2017. https://endpts.com/pharmas-broken-business-model-an-industry-on-the-brink-of-terminal-decline/ (last accessed February 23, 2018).

54 de la Merced MJ, Abelson R: CVS to buy Aetna for $\$ 69$ billion in a deal that may reshape the health industry. New York Times, March 12, 2017. https://www.nytimes.com/2017/12/03/business/dealbook/cvs-is-saidto-agree-to-buy-aetna-reshaping-health-care-industry.html (last accessed February 23, 2018).

55 PWC: Patient engagement: pharma's strategy for success in the New Health Economy. 2016. https://www. pwc.com/us/en/health-industries/health-research-institute/publications/new-patient-engagement.html (last accessed February 23, 2018).

56 Giggins OM, Clay I, Walsh L: Physical activity monitoring in patients with neurological disorders: a review of novel body-worn devices. Digit Biomark 2017;1:14-42.

57 Burbulla LF, Song P, Mazzulli JR, Zampese E, Wong YC, Jeon S, et al: Dopamine oxidation mediates mitochondrial and lysosomal dysfunction in Parkinson's disease. Science 2017;357:1255-1261. 